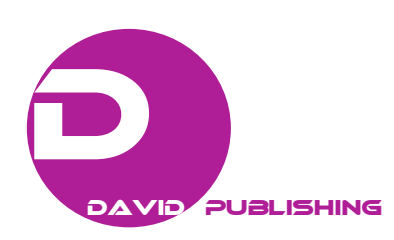

\title{
Analysis of Waste in the Production of Concrete Blocks-A Case Study in the Goiás Industry
}

\author{
Tatiana Gondim do Amaral, Weslley M. Cruz and José R. Perim \\ Department of Civil Engineering , Federal University of Goiás, Goiânia 74605-220, Brazil
}

\begin{abstract}
An ever more demanding consumer market and the need for companies to be more competitive have led organizations to try to eliminate waste. This research is a case study which presents a proposal for intervention in order to improve performance of a pre-cast concrete block factory in outer Goiânia. As a first step, waste in the production process was identified through analysis of data on time involved in each step of the process. Then, applying the concepts of lean production, a list of activities was drawn up with a view to eliminating non-value-added work, identifying waste, decreasing cycle time, streamlining the production process and increasing the flexibility and transparency of the process. From the results, it was possible to identify the sources of waste and provide management with information for strategic decisions about production. Finally, various suggestions were made with a view to eliminating or mitigating bottlenecks in the production process.
\end{abstract}

Key words: Lean production, waste, concrete blocks, continuous improvement.

\section{Introduction}

From the late 1970s onwards, many industries underwent profound changes in the organization of their productive activities, which led to the establishment of new paradigms of production management. Many of these proposed changes in the new paradigm initially emerged in the Japanese automobile industry, and were broadly applied by Toyota Production System [1-4]. Koskela [5] conceptualized, adapted this new paradigm of production management for the construction industry and called it lean construction.

Lean production is so called because it uses smaller amounts of everything when compared to mass production: half of the factory workers' labor, half of the investment in tooling, half of the time spent planning to develop new products. It also means fewer inventories at the factory, and results in lower rates of product defects and a larger expanding variety of products [6-8].

Corresponding author: Tatiana Gondim do Amaral, Ph.D., professor, research field: management in construction. E-mail: tatiana_amaral@hotmail.com.
In addition to the basic concepts, lean production presents a set of principles for the management of processes, some of which are now presented: reduce the work which does not add value; enhance product value by considering consumer needs; reduce variability; reduce cycle time; simplify by reducing the number of steps and parts; increase output flexibility; increase process transparency; focus on control of the overall process; introduce ongoing improvement to the process; balance flow and conversion improvement; benchmark [9, 10].

It is worth noting that if these principles for improving processes are to be deployed, requirements, such as commitment on the part of top management, a focus on measurable and viable improvements, employee involvement and continuous formation are necessary.

According to Refs. [8, 11], the premises of lean principles are basic, namely, to plan a production system to deliver a product instantly without maintaining any intermediate stocks. The concepts include identifying and giving the consumer value, eliminating everything which does not add value, organizing production as a continuous flow, posting 
information and delegating decision-making, pursuing perfection, delivering a product answering the requirements of consumers and leaving zero inventory.

In Refs. $[8,12]$ and class notes, ${ }^{1}$ it is possible to improve organizational objectives through lean production by keeping the various activities in constant motion, maintaining the various activities working (at the same rate) over time, avoiding peaks and valleys in production, using consumer requirements to determine how activities are performed, anticipating the needs of production and consumers, foreseeing the needs of production and consumers since foresight is the motive for both, recognizing the unpredictability of processes, and maintaining ongoing negotiation between the needs dictated by production and the possibilities of implementing them, seeing to an increase in continuity of operations by reducing variability, coordinating the flow of resources and operations so that variations outside the scope of management during the process can be avoided, reducing waste in the processes, understanding waste as all that is not consistent with a balance between the aims and the means chosen in each circumstance.

\section{Waste}

The logic of the Toyota Production System, advocated by Ohno [9], seeks to identify and eliminate all the waste which occurs during the value chain of the product/service. According to Ohno [9], there must be a full understanding of the concept of waste, so that it can be detected and completely eliminated. According to him, it is necessary to divide the worker's involvement into two different dimensions: work and waste. Work can be subdivided into two groups: effective work which adds value and extra work which does not add value. Then the rate of work which adds value should be increased through eliminating waste, minimizing additional work and maximizing effective work.

\footnotetext{
${ }^{1}$ Heineck, L. F. M., and Machado, R. L. 1998. Considerations on the Concept of Lean Construction and the Proposition of an Information System Model.
}

As a basis for the systematic process of identifying and eliminating waste, Ohno [9] and Shingo [10] propose seven classes of waste:

(1) Waste through overproduction — which can be further divided into quantitative and anticipated waste: quantitative overproduction is waste due to the production of more than the volume programmed while waste caused by anticipated overproduction is waste brought about by producing material before it is needed;

(2) Waste due to transportation-all transport is waste and is ultimately optimized by total elimination;

(3) Waste due to the processing itself-those processing activities which are not needed for the product/service to acquire the characteristics desired or specified by the consumer;

(4) Waste due to manufacture of defective products - the production of parts, subcomponents or finished products which do not meet the quality specifications required by the project;

(5) Waste due to motion-the unnecessary movements made by operators while executing an operation;

(6) Waste due to waiting - there are two types: waste due to a delay in the process, which arises, for example, when a whole consignment awaits dispatching while the previous one is still being processed, inspected or transported; waste caused by waiting for a consignment which happens, for example, when the components of a consignment wait until the processing of the entire consignment has been completed;

(7) Waste due to inventory-the holding of inventory of raw materials, work-in-progress or finished goods.

\section{Methodology}

The company in this case study is a medium-sized producer of pre-cast concrete blocks, located in the city of Goiânia, State of Goiás, Brazil.

Concrete blocks for construction and interlocking concrete flooring are manufactured using vibro-pressing equipment, Piorotti Blocopac 900 and 
750, respectively. Production is continuous, starting with the input of raw materials (cement, aggregates, water and pigment) at one end and ending with the product outlet at the other. A process flow chart is shown in Fig. 1.
The materials used in production are: natural sand, artificial sand, gravel (maximum diameter of $9.5 \mathrm{~mm}$ ), coarse aggregate (maximum diameter $12.5 \mathrm{~mm}$ ), CPII F-32 CIMPOR cement, water, pigments and additives. All coarse and fine aggregates are stored in bays, and

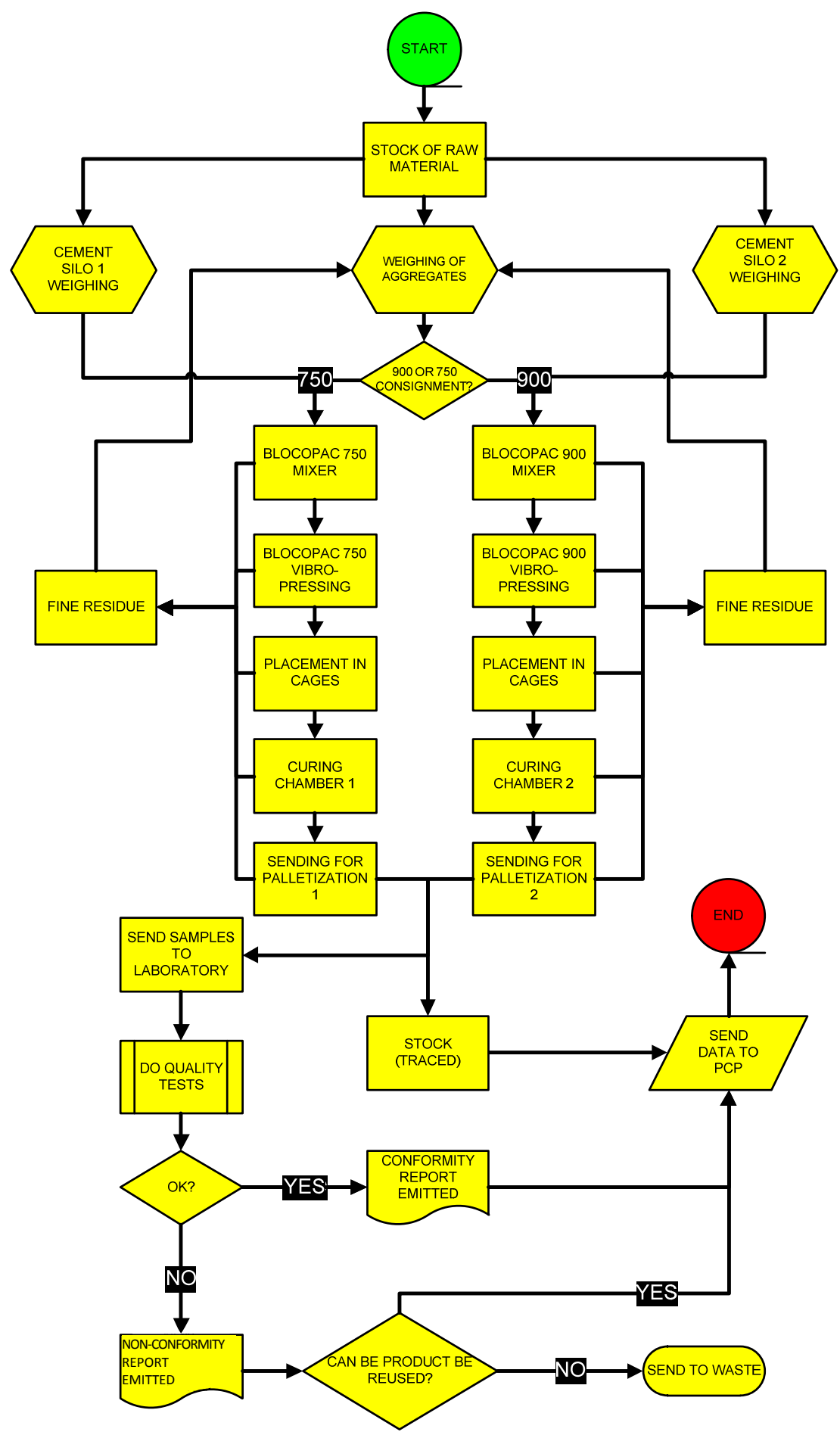

Fig. 1 A flow chart of manufacture of blocks and interlocking concrete flooring. 
the former are, in some cases, laid out in side bays for drying out purposes. Cement is stored in two metal silos, both of which are located next to the mixer of each vibro-press machine.

Fig. 2 shows the aggregate storage bays and the measuring station.

First, the aggregates are measured in a station equipped with a conveyor belt with a load cell. After weighing, the aggregates are transferred to the mixers by means of two conveyor belts, one inclined and the other horizontal. Cement, water and additives are added to the mixers. After mixing, the concrete is poured into the machine and vibro-pressed on metal plates. The final product is placed in wire cages and sent to the curing chamber. In the following day, the products are sent for palletizing and placed in storage. Fig. 3 shows the stages of vibro-pressing, chamber drying and palletizing of blocks.

Constant interruptions in the production process, resulting in a failure to reach production targets, was the reason why the waste inherent in the process was analyzed. A survey of the time spent was done in the following stages of the production process in the Blocopac 900 machine: (1) weighing; (2) Conveyor
Handling 1; (3) mixing; (4) vibro-pressing; (5) Conveyor Handling 2; (6) placing in the wire cage. The average time for each stage and their respective standard deviations were recorded. These data were collected during the last week of October and first week of November 2010.

Improvements which could be implemented in the overall process were analyzed, using a brainstorming technique with the engineers responsible for quality control and with the environment manager. Fig. 4 shows the Piorotti factory layout.

Data were collected and measured by consignment, while times for vibro-pressing, Conveyor Belt Handling 2 and placing in the wire cage were measured for one machine cycle. This meant that the time spent on all the selected stages could not be evaluated. It was decided to adapt the time by multiplying the cycle time by the average of cycles per consignment on each of the days studied.

\section{Analysis of Results}

Two graphs of the times found were made for analysis purposes: one is a bar chart, where the times of each consignment in each of the stages were compared;

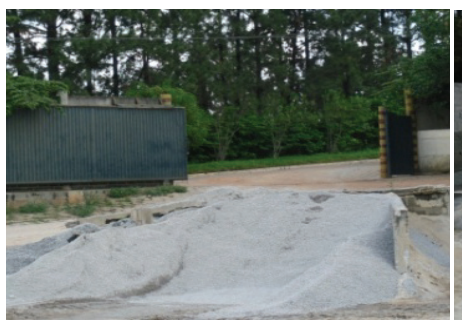

(a)

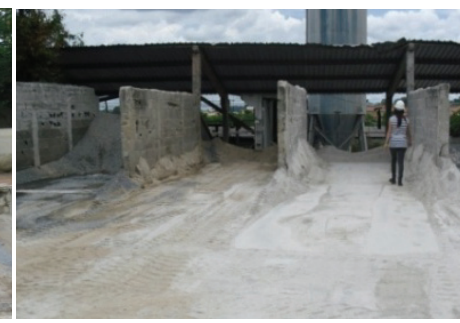

(b)

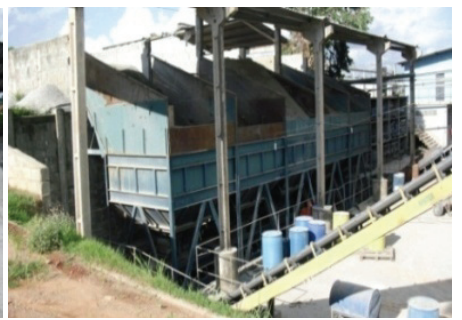

(c)

Fig. 2 Aggregate storage bays and the measuring station: (a) drying bays ("rest"); (b) storage bays; (c) measurement stations.

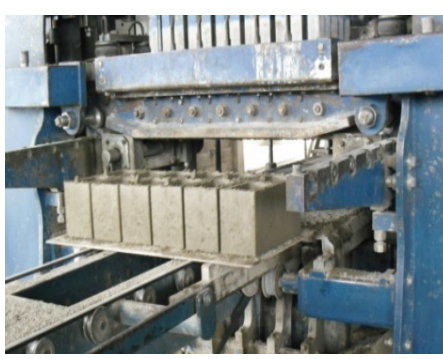

(a)

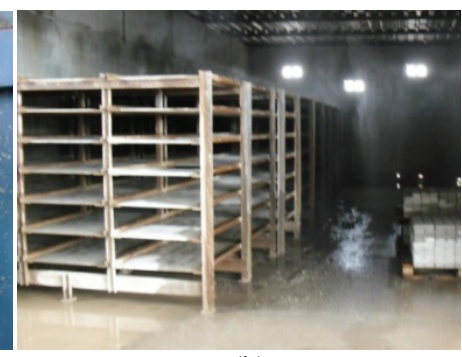

(b)

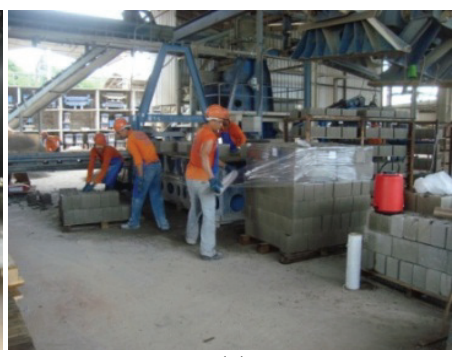

(c)

Fig. 3 Stages of vibro-pressing, chamber drying and palletizing of blocks: (a) exit of blocks from Blocopac 900; (b) drying chamber; (c) block palletizing. 


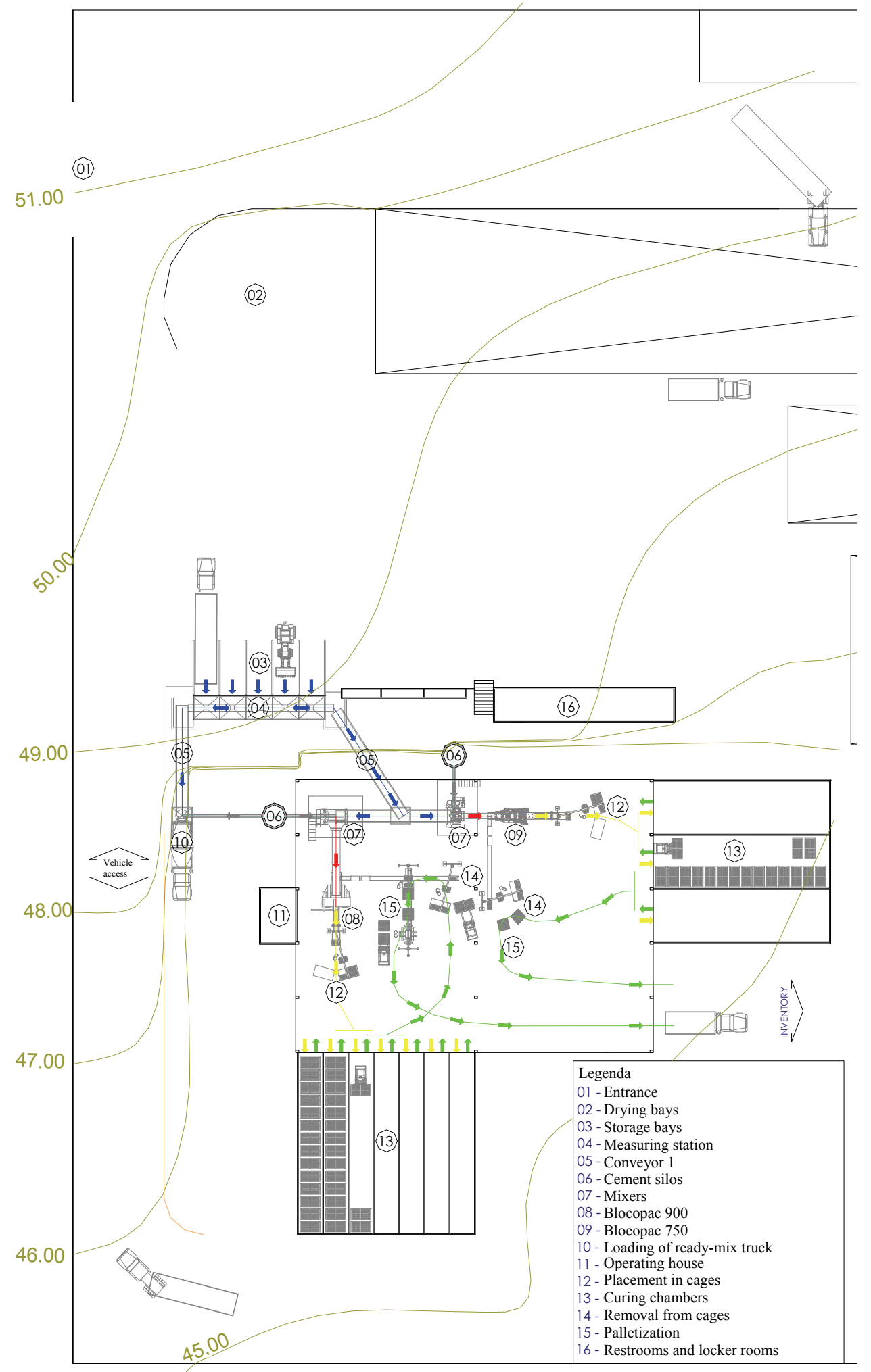

Fig. 4 Layout of the Piorotti factory. 
and the other is a pie chart, which showed the average amount of time spent on each stage. The standard deviations found in each stage was also calculated.

The data would indicate that there is a tendency towards a reduction in time spent going from the vibro-pressing stage to that of placement in the wire cages for each period analyzed (Figs. 5-8). About the data presented in Fig. 9, this is not clear for the two consignments. This difference could be explained by the adaptation done to get the total time for placement in the cage, described in the previous section.

This difference is more evident in the placement stage, as it is subject to time change due to the considerable variation in time that can occur while placing the plates in the cage. In these graphs, it shows that there is no upward or downward linear tendency, when comparing the times for the weighing, Conveyor Handling 1, and mixing stages for each day.

In pie charts of the Figs. 5-9, it shows that data about the times for vibro-pressing took up the greatest part of the total stage of each day (between $23 \%$ and $31 \%$ ), as well as giving rise to the largest standard deviations (ranging from $15 \%$ to $31 \%$ ). Since vibro-pressing is an automatic stage requiring minimal human interference, it can be concluded that there is poor adjustment or loss of work parameters. This deficiency could be explained by the erroneous introduction of parameters and/or loss of adjustment, throughout the day, due to a lack of preventive maintenance or training of employees.

The data in Fig. 5 show that the stages of weighing and Conveyor Handling1 occupy in all more than half the length of time spent on vibro-pressing. This shows the probability of a shortage of material for mixing if the station is concomitantly weighing consignments for the other machine (Blocopac 750). However, in the data for the other days (Figs. 6-9), that did not happen. The quality control team noticed that when the aggregates in the bays are very wet, it is difficult for the material to fall from the station silos onto the weighing conveyor, and to fall from the Conveyor Handling 1 into the mixer. This highlights the need to expand, adapt the layout and adjust the rest bays, for drying the material arriving, and also the need to cover the bays to protect the aggregates from the rain.

(a) Table - Sampletime of Blocopac 900 times

\begin{tabular}{|c|c|c|c|c|c|c|c|c|c|c|c|}
\hline \multicolumn{4}{|c|}{ PRODUCT: $2.5 \mathrm{MPa} 14 \times 19 \times 39 \mathrm{~cm}$ Cavity blocks } & \multicolumn{2}{|c|}{1159} & \multirow{2}{*}{$\begin{array}{l}\text { kgs } \\
\text { units }\end{array}$} & & & & & \\
\hline № 50PA271010 & Cycles & 1360 & & & 87 & & & & & & \\
\hline \multirow{3}{*}{$\begin{array}{l}\text { Date: } 27 / 102010 \\
\text { Stages }\end{array}$} & \multirow{2}{*}{\multicolumn{2}{|c|}{$\frac{\text { Consignment } 1}{\text { time }(\min )}$}} & \multirow{2}{*}{\multicolumn{2}{|c|}{$\begin{array}{c}\text { Consignment } 2 \\
\text { time (min) }\end{array}$}} & \multirow{2}{*}{\multicolumn{2}{|c|}{$\begin{array}{c}\text { Consignment } 3 \\
\text { time (min) }\end{array}$}} & \multirow{2}{*}{\multicolumn{2}{|c|}{$\begin{array}{c}\text { Consignment } 4 \\
\text { time (min) }\end{array}$}} & \multicolumn{3}{|c|}{ Average time } \\
\hline & & & & & & & & & \multicolumn{2}{|c|}{ time $(\min )$} & \\
\hline & indiv. & acum. & indiv. & acum. & indiv. & acum. & indiv. & acum. & indiv. & acum. & Deviation \\
\hline Weighing & 2.3 & 2.3 & 2.1 & 2.1 & 2.2 & 2.2 & & & 2.2 & 2.2 & 0.09 \\
\hline Conveyor handling 1 & 2.2 & 4.5 & 2.2 & 4.3 & 2.2 & 4.4 & & & 2.2 & 4.4 & 0.00 \\
\hline Mixing & 1.7 & 6.2 & 1.7 & 6.0 & 1.5 & 5.9 & & & 1.6 & 6.0 & 0.12 \\
\hline Vibro-pressing & 3.1 & 9.3 & 2.9 & 8.9 & 2.9 & 8.7 & & & 3.0 & 9.0 & 0.15 \\
\hline Conveyor handling 2 & 2.3 & 11.7 & 2.3 & 11.2 & 2.3 & 11.1 & & & 2.3 & 11.3 & 0.00 \\
\hline Placing in wire cage & 1.8 & 13.5 & 1.8 & 13.1 & 1.6 & 12.6 & & & 1.7 & 13.1 & 0.15 \\
\hline Total time (min) & & 13.5 & & 13.1 & & 12.6 & & & & 13.1 & \\
\hline
\end{tabular}

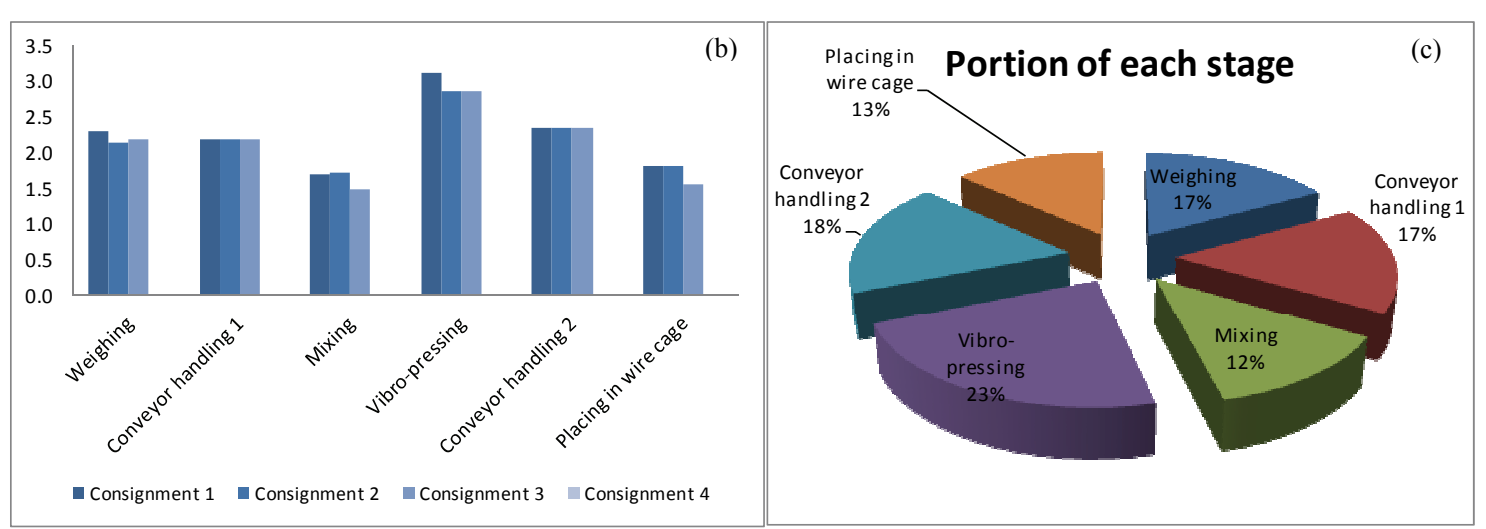

Fig. 5 Data for time spent making $2.5 \mathrm{MPa}, 14 \mathrm{~cm} \times 19 \mathrm{~cm} \times 39 \mathrm{~cm}$ cavity blocks: (a) table with times for each consignment and stage; (b) bar chart showing time for each consignment at each stage; (c) pie chart showing average times for each stage. 
(a) Table - Sampletime of Blocopac 900 times

\begin{tabular}{|c|c|c|c|c|c|c|c|c|c|c|c|}
\hline \multicolumn{4}{|c|}{ PRODUCT: 4.5MPa 14x19x29 cm Cavity blocks } & \multicolumn{2}{|c|}{ Consignment 1620} & \multirow{2}{*}{$\begin{array}{l}\text { kgs } \\
\text { units }\end{array}$} & & & & & \\
\hline $\mathbf{N}^{\circ}$ 52PA281010 & Cycles & 1500 & & consignime & 1 56 & & & & & & \\
\hline Date: $28 / 102010$ & Consign & $\overline{\text { nent } 1}$ & Consign & ment 2 & Consign & ment 3 & Consign & nent 4 & & rage tin & \\
\hline Stages & time 1 & $\operatorname{nin)}$ & time ( & $\min )$ & time & $\min )$ & time & $\min )$ & time & $\min )$ & \\
\hline & indiv. & acum. & indiv. & acum. & indiv. & acum. & indiv. & acum. & indiv. & acum. & Deviation \\
\hline Weighing & 2.0 & 2.0 & 1.9 & 1.9 & 1.9 & 1.9 & 1.8 & 1.8 & 1.9 & 1.9 & 0.05 \\
\hline Conveyor handling 1 & 1.8 & 3.7 & 1.8 & 3.7 & 1.7 & 3.7 & 1.8 & 3.6 & 1.8 & 3.7 & 0.03 \\
\hline Mixing & 1.9 & 5.6 & 1.9 & 5.6 & 1.9 & 5.5 & 1.9 & 5.5 & 1.9 & 5.5 & 0.02 \\
\hline Vibro-pressing & 5.4 & 10.9 & 4.9 & 10.5 & 4.9 & 10.4 & 5.4 & 10.8 & 5.1 & 10.7 & 0.26 \\
\hline Conveyor handling 2 & 4.0 & 15.0 & 4.0 & 14.5 & 4.0 & 14.5 & 4.0 & 14.8 & 4.0 & 14.7 & 0.00 \\
\hline Placing in wire cage & 3.1 & 18.1 & 3.1 & 17.6 & 3.1 & 17.6 & 3.1 & 18.0 & 3.1 & 17.8 & 0.00 \\
\hline Total time (min) & & 18.1 & & 17.6 & & 17.6 & & 18.0 & & 17.8 & \\
\hline
\end{tabular}

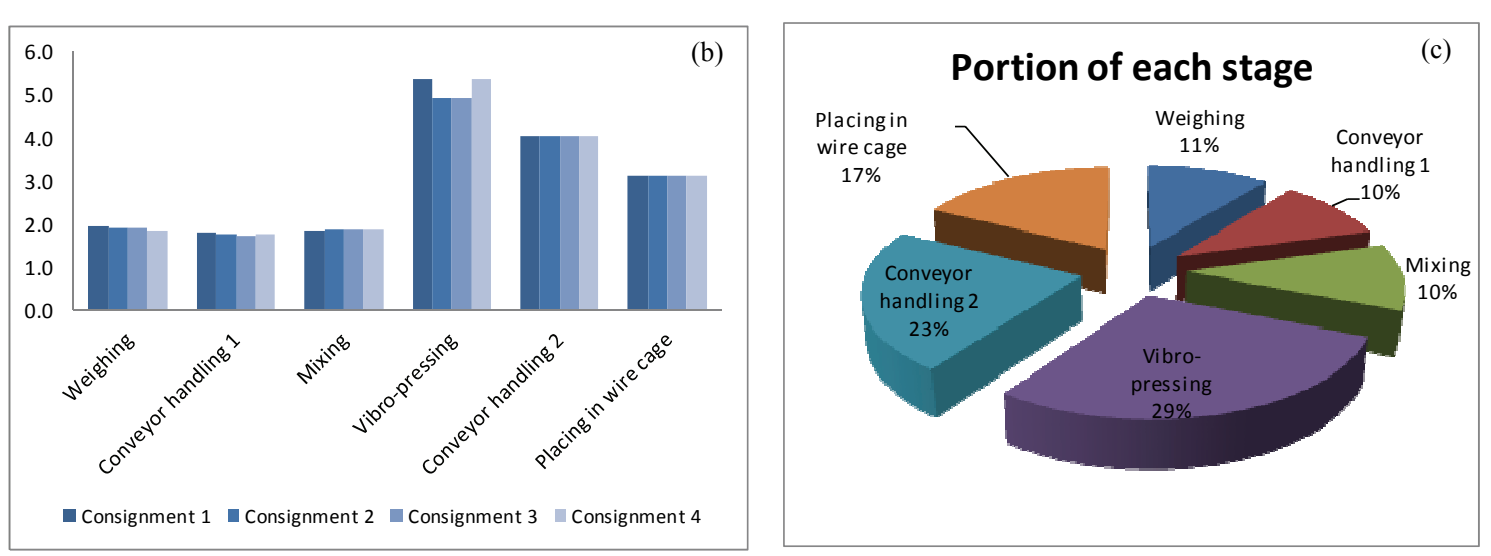

Fig. 6 Data for time spent making $4.5 \mathrm{MPa}, 14 \mathrm{~cm} \times 19 \mathrm{~cm} \times 29 \mathrm{~cm}$ cavity blocks: (a) table with times for each consignment and stage; (b) bar chart showing time for each consignment at each stage; (c) pie chart showing average times for each stage.

(a) Table - Sampletime of Blocopac 900 times

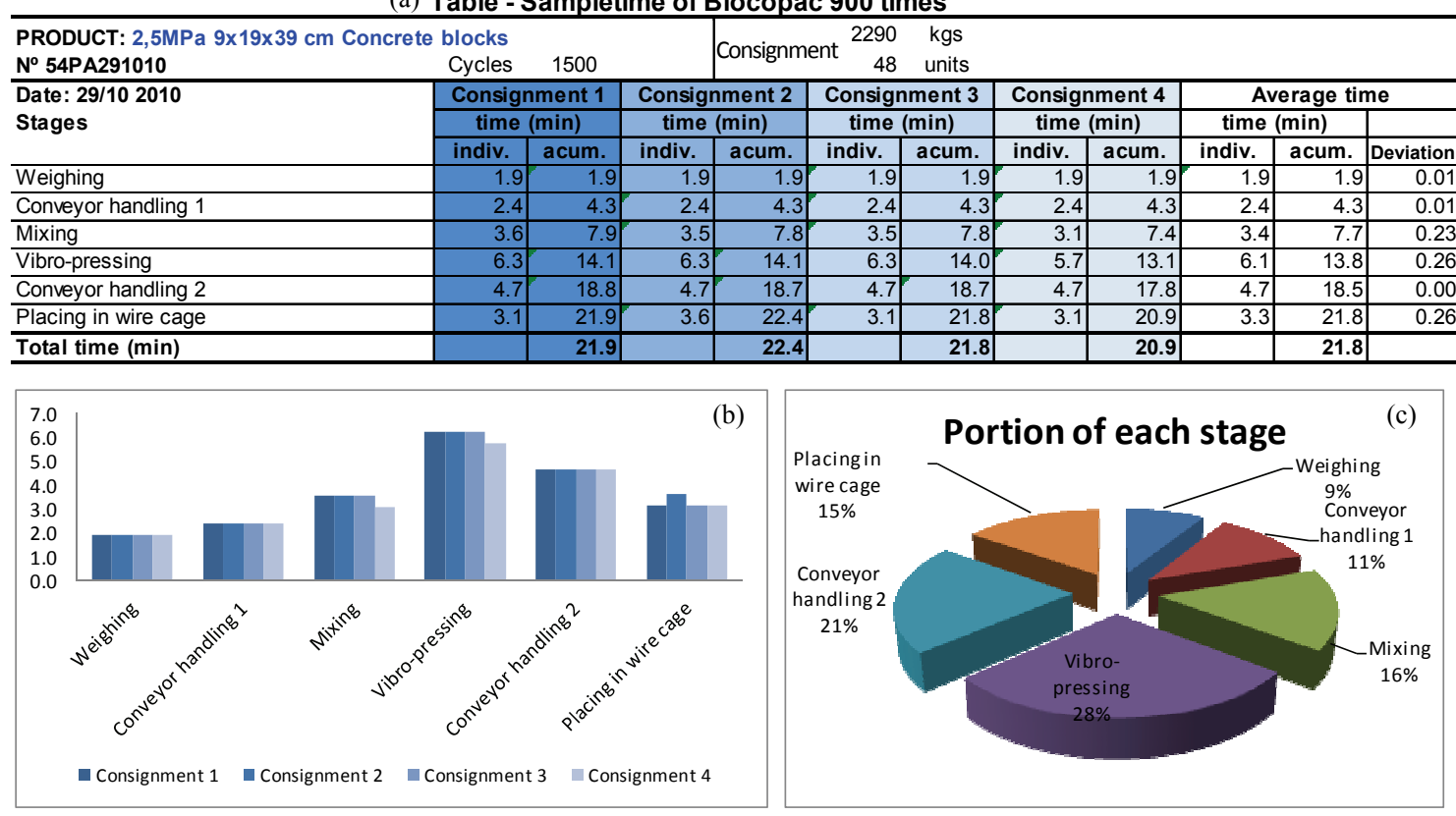

Fig. 7 Data for time spent making $2.5 \mathrm{MPa}, 9 \mathrm{~cm} \times 19 \mathrm{~cm} \times 39 \mathrm{~cm}$ concrete blocks: (a) table with times for each consignment and stage; (b) bar chart showing time for each consignment at each stage; (c) pie chart showing average times for each stage. 
(a) Table - Sampletime of Blocopac 900 times

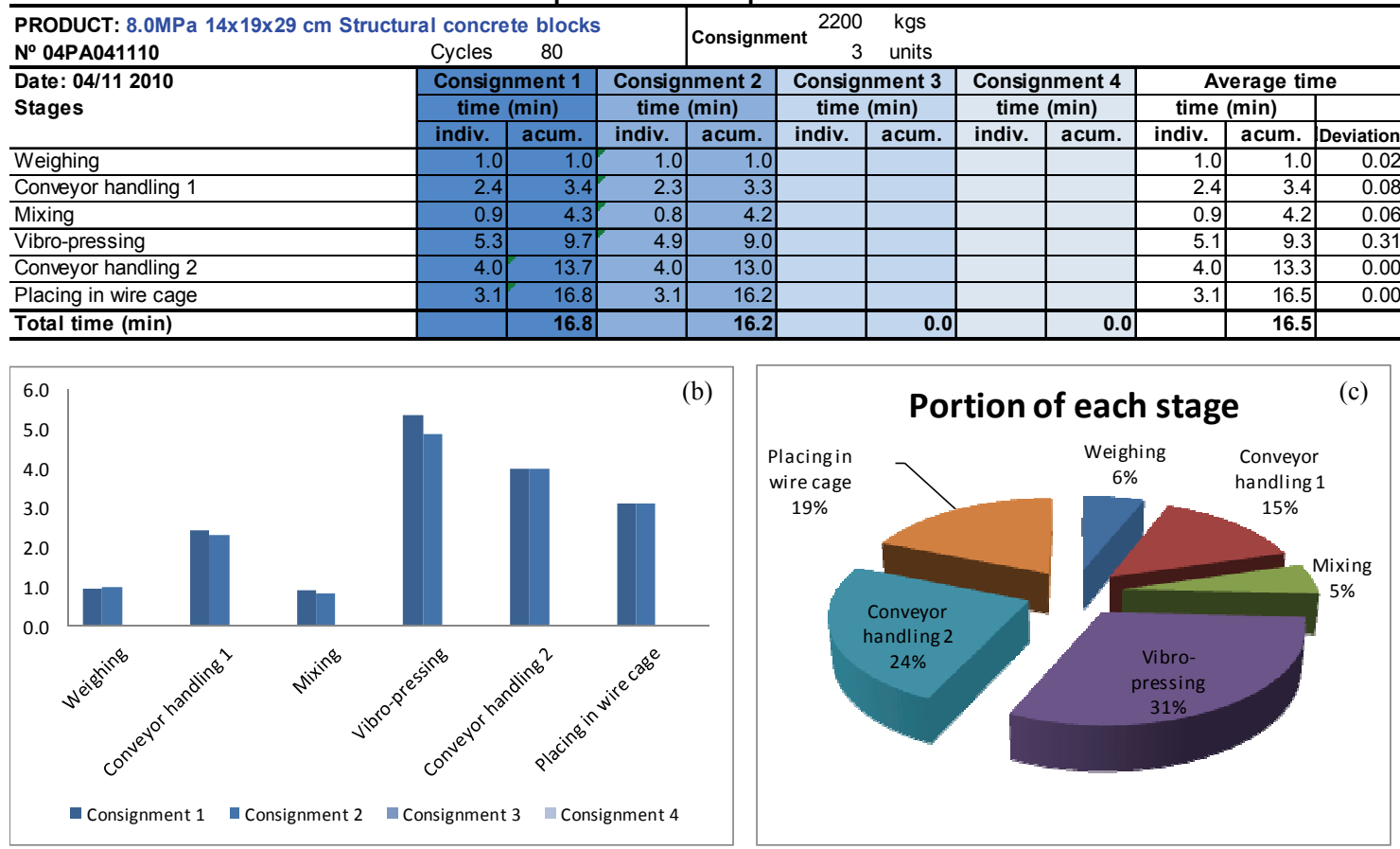

Fig. 8 Data for time spent making $8.0 \mathrm{MPa}, 14 \mathrm{~cm} \times 19 \mathrm{~cm} \times 29 \mathrm{~cm}$ structural concrete blocks: (a) table with times for each consignment and stage; (b) bar chart showing time for each consignment at each stage; (c) pie chart showing average times for each stage.

(a) Table - Sampletime of Blocopac 900 times

\begin{tabular}{|c|c|c|c|c|c|c|c|c|c|c|c|}
\hline \multicolumn{4}{|c|}{ PRODUCT: $2,5 \mathrm{MPa} 9 \times 19 \times 29 \mathrm{~cm}$ Concrete block } & \multirow{2}{*}{\multicolumn{8}{|c|}{$\begin{array}{lrl} & 2280 & \text { kgs } \\
\text { Consignment } & 8 & \text { units }\end{array}$}} \\
\hline $\mathrm{N}^{\circ}$ 06PA051110 & Cycles & 270 & & & & & & & & & \\
\hline \multirow{3}{*}{$\begin{array}{l}\text { Date: } 05 / 112010 \\
\text { Stages }\end{array}$} & \multirow{2}{*}{\multicolumn{2}{|c|}{$\frac{\text { Consignment } 1}{\text { tempo }(\mathrm{min})}$}} & \multirow{2}{*}{\multicolumn{2}{|c|}{\begin{tabular}{|c|} 
Consignment 2 \\
tempo (min)
\end{tabular}}} & \multirow{2}{*}{\multicolumn{2}{|c|}{$\begin{array}{c}\text { Consignment } 3 \\
\text { tempo }(\mathrm{min})\end{array}$}} & \multirow{2}{*}{\multicolumn{2}{|c|}{$\begin{array}{c}\text { Consignment } 4 \\
\text { tempo (min) }\end{array}$}} & \multicolumn{3}{|c|}{ Average time } \\
\hline & & & & & & & & & \multicolumn{2}{|c|}{ tempo (min) } & \\
\hline & indiv. & acum. & indiv. & acum. & indiv. & acum. & indiv. & acum. & indiv. & acum. & Deviation \\
\hline Weighing & 2.1 & 2.1 & 2.0 & 2.0 & 2.1 & 2.1 & 2.1 & 2.1 & 2.1 & 2.1 & 0.02 \\
\hline Conveyor handling 1 & 1.1 & 3.2 & 1.1 & 3.2 & 1.1 & 3.2 & 1.1 & 3.2 & 1.1 & 3.2 & 0.02 \\
\hline Mixing & 2.3 & 5.4 & 2.6 & 5.8 & 2.8 & 6.0 & 2.0 & 5.2 & 2.4 & 5.6 & 0.35 \\
\hline Vibro-pressing & 6.2 & 11.6 & 6.8 & 12.5 & 6.8 & 12.7 & 6.8 & 11.9 & 6.6 & 12.2 & 0.28 \\
\hline Conveyor handling 2 & 5.1 & 16.7 & 5.1 & 17.6 & 5.1 & 17.8 & 5.1 & 17.0 & 5.1 & 17.3 & 0.00 \\
\hline Placing in wire cage & 3.9 & 20.6 & 3.4 & 21.0 & 5.1 & 22.9 & 5.1 & 22.1 & 4.4 & 21.6 & 0.84 \\
\hline Total time $(\min )$ & & 20.6 & & 21.0 & & 22.9 & & 22.1 & & 21.6 & \\
\hline
\end{tabular}

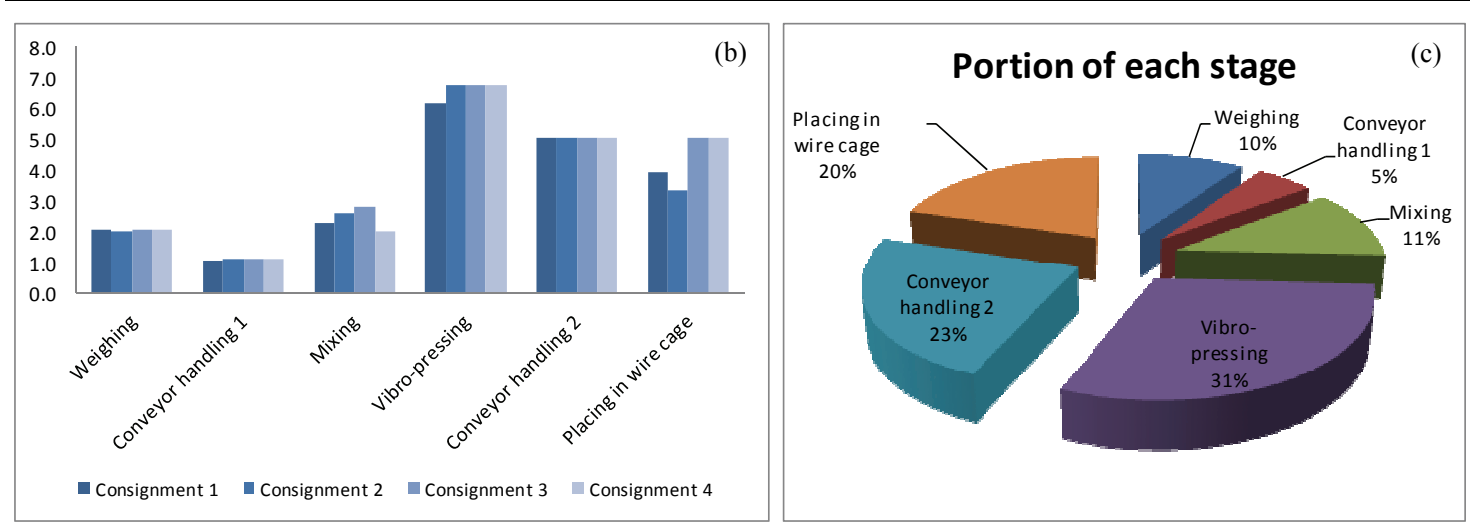

NB: The sensor was not releasing the mixture because it was covered with residue and gave the impression that mixer was still full and did not need to release the mixture. For this reason, there is a increase in time in some cases.

Fig. 9 Data for time spent making $2.5 \mathrm{MPa}, 9 \mathrm{~cm} \times 19 \mathrm{~cm} \times 29 \mathrm{~cm}$ concrete blocks: (a) table with times for each consignment and stage; (b) bar chart showing time for each consignment at each stage; (c) pie chart showing average times for each stage. 
As regards the mixing time, it shows, from the bar and pie charts of Figs. 5-9, that there is a wide variation between the days (ranging from $0.8 \mathrm{~min}$ to $3.6 \mathrm{~min}$ ) and the tables show large standard deviations for the mixing stage. It was noted that the wide variation in the mixing times is due to the two sensors in the mixer. One of these measures the moisture of the material inside the mixer, which means that the quantity of water to be used in the mixture can be automatically calculated, is based on the parameter of the total amount of water in the consignment. It shows that waste mortar constantly accumulates on the sensor, to the extent that it affects the calculation of the amount of incoming water. The other sensor indicates whether the mixer contains material, allowing the hatch to close and begin weighing the components of the next consignment. However, when there is material covering this sensor, the system understands that there is still material in the mixer, so it does not give the go-ahead to the sequence and thereby increases the mixing time. These interferences need to be corrected so that the streamlining of the work of the sensors is not thwarted.

Besides the above-mentioned interruptions in weighing, the weight of the ready-mix truck also substantially interferes with the process. This truck supplies concrete to that part of the company making pre-cast concrete structures. The loading of this truck should be transferred to another station so as not to interrupt the weighing process of the vibro-pressing machines.

The graph in Fig. 10 shows the variation of the standard deviations for each stage on the 5 days in which they were measured. It is evident that the Conveyor Handling 2 stage presented the lowest standard deviations and showed a continuous linear trend. The mixing stage presented deviation variations and the vibro-pressing stage presented the highest values of standard deviation. The placement in the cage stage showed marked variations, but this can be explained by the adjustments made as explained earlier.

From the analysis of these data, a series of actions can be proposed to eliminate production bottlenecks:

- improve the layout (removal of concrete mixing shed and improved access ramp) in order to make the discharge of raw material (aggregates and cement) more efficient, as suggested in Fig. 11;

- building of bays with a drainage system for drying out aggregates;

- roofing of rest and storage bays to reduce moisture in aggregates;

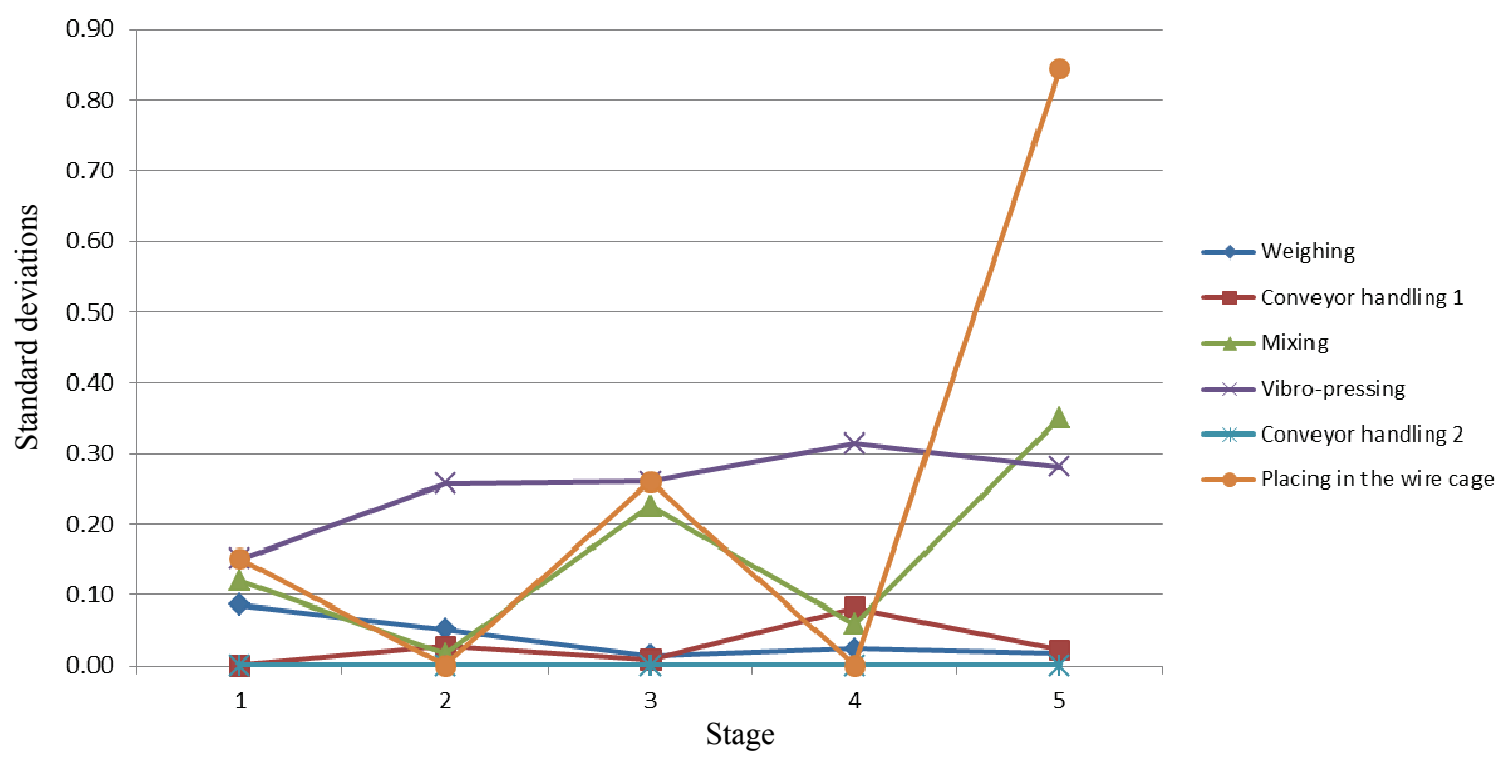

Fig. 10 Line graph for the standard deviations of mean times in each of the stages analyzed. 


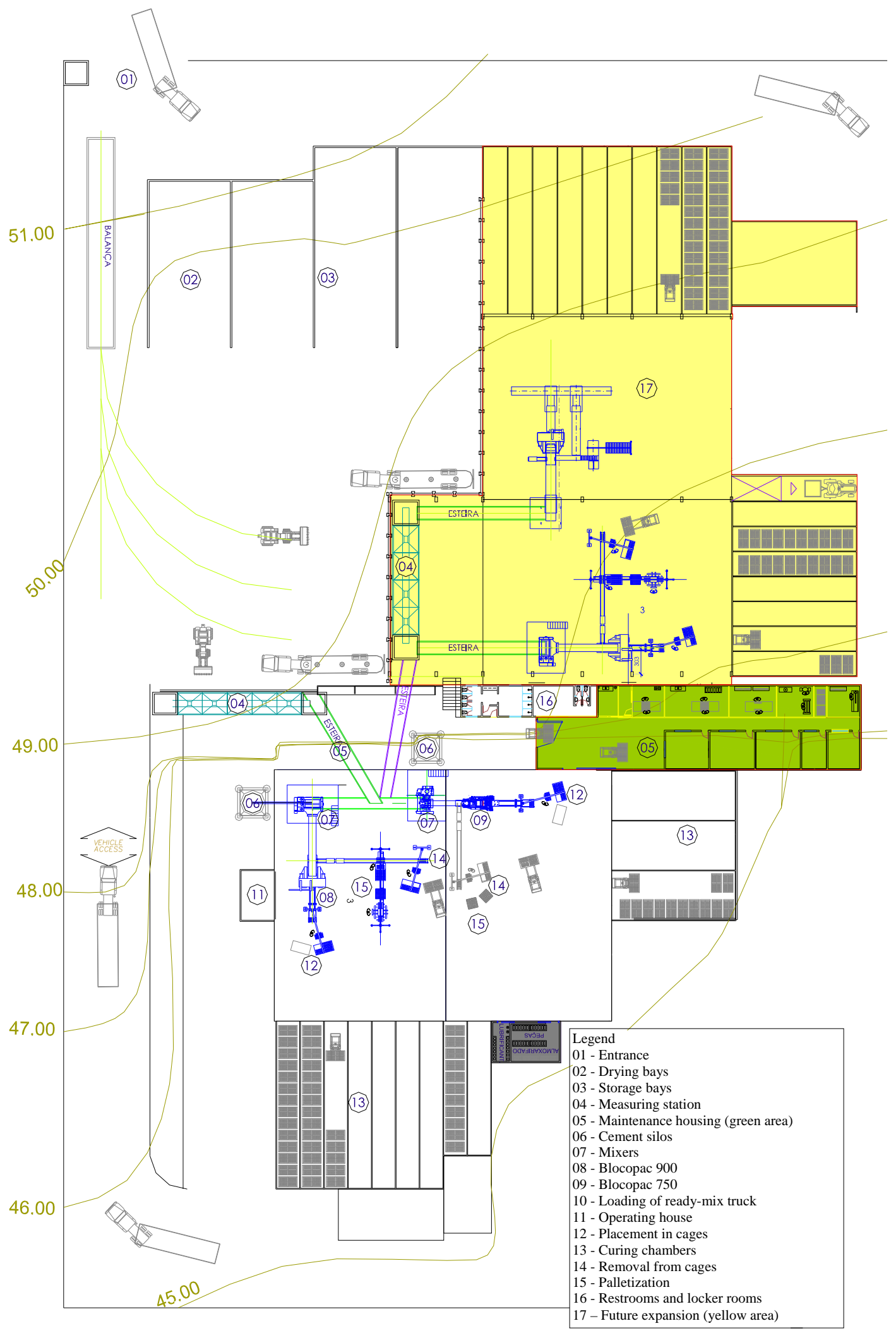

Fig. 11 Suggested layout with proposed changes. 
- trials to check aggregate quality parameters in order to adjust consignments using quality control;

- strict inspection and carrying out of preventive maintenance in machinery and equipment in order to avoid unwanted downtime and corrective maintenance;

- quality control as the product leaves the machine, prior to curing, in order to minimize the quantity of non-conforming products;

- setting automation in order to reduce human intervention in the process of mixing and release of concrete, thereby solving the problem of the sensors;

- continuous training for all employees involved in the production process;

- establishment of productivity goals, incentives for reaching the objectives established and reports with indicators for greater control of the whole process;

- increased transparency in the process, placing the information necessary for successful production (production schedule, product, consignment, period, etc.) at the disposal of all;

- improved transport flow in the moist curing chamber, where products will flow in a continuous, orderly and sequential manner;

- improved storage of deliverables so that loading for the end consumer is done optimally and sequentially.

\section{Conclusions}

Applying the principles of lean production lead to the identification of those parts which do not add value, recognition of waste in the productive process and suggestions for improvement. The main waste in the production process was analyzed and found to be caused by inventory, transport and handling, waiting and in the processing itself. By implementing the made suggestions, other benefits can be reaped, such as reduced cycle time, improved production flow balance and increased transparency in the process. The obtained information provides the management with subsidies for making decisions about production strategies.
However, efforts must be intensified and, for better results, there should be a focus on checking the overall process. Control of the production process should be used in a systemic way and ideals should be circulated among employees.

A suggestion for future studies would be to trace and cross reference data on variations in time spent making the product with their respective normative resistance results.

\section{References}

[1] Neto, J. P. B., Alves, T. C. L., and Abreu, L. V. M. 2007. "Strategic Aspects of Lean Construction." Presented at the 5th Brazilian Symposium on Management and Economics Building, Campinas. (in Portuguese)

[2] Bernardes, M. M. S. 2001. "Development of a Model for Planning and Production Control for Micro and Small Construction Companies.” Post graduate degree program in Civil Engineering, Federal University of Rio Grande do Sul. (in Portuguese)

[3] Picchi, F. A. 2003. "Opportunities Application of Lean Thinking in Construction.” Built Environment Magazine 3 (1): 7-23. (in Portuguese)

[4] Picchi, F. A., and Granja, A. D. 2004. "Application of Lean Thinking to the flow of work." Presented at the 1st Latin American Conference on Sustainable Building Technology, National Meeting of the Built Environment, São Paulo. (in Portuguese)

[5] Koskela, L. 1992. Application of the New Production Philosophy to Construction. Technical report No. 72, Stanford University.

[6] Womack, J. P., and Jones, D. T. 1999. Learning to See: Mapping the Value Stream to Add Value and Eliminate Waste. Massachusetts: The Lean Enterprise Institute.

[7] Womack, J. P., Jones, D. T., and Ross, D. 2004. The Machine That Changed the World: Based on the Massachusetts Institute of Technology Study on the Future of the Automobile. 10th ed.. USA: Elsevier Press.

[8] Do Amaral, T. G. 2004. "Qualification Methodology for Construction Workers on the Basis of Managerial Knowledge of Lean Construction.” Doctor thesis, Federal University of Santa Catarina. (in Portuguese)

[9] Ohno, T. 1997. The Toyota Production System: Beyond Large-Scale Production. Porto Alegre: Bookman. (in Portuguese)

[10] Shingo, S. 1996. The Toyota Production System: From the Point of View of Production Engineering. Porto Alegre: Bookman. (in Portuguese)

[11] Howell, G. A. 1999. "What Is Lean Construction-1999." 
In Proceedings of Conference of the International Group for Lean Construction, 11-7.

[12] Heineck, L. F. M., and Machado, R. L. 1998. Considerations on the concept of lean construction and the proposition of an information system model, Class notes (1998). (in Portuguese)
[13] Heineck, L. F. M., Costa, A. C. F., dos Santos, R. B., de Lima, F. B., and Jungles, A. E. 2005. "Physical Flows Management in the Construction Processes of Construction Sites-Buildings." Presented at the 4th Brazilian Symposium on Management and Economics Building and I ELAGEC, Porto Alegre. (in Portuguese) 